\title{
EL PAPEL DEL ESTADO Y CIUDADANÍA FRENTE A LA CORRELACIÓN EN LOS DERECHOS HUMANOS
}

Martha Charris Balcázar Antonio Yesid Pedroza Estrada

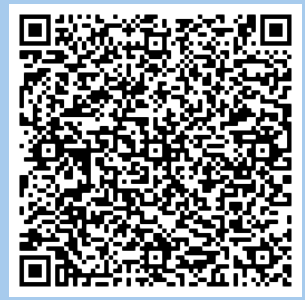




\title{
EL PAPEL DEL ESTADO Y GIUDADANÍA FRENTE A LA CORRELAGIÓN EN LOS DEREGHOS HUMANOS
}

\author{
Martha Charris Balcázar ${ }^{1}$, Antonio Yesid Pedroza Estrada
}

\section{Palabras clave \\ Derechos Humanos, correlatividad, ciudadano.}

\section{RESUMEN}

Todo ser humano, por este hecho, tiene derechos básicos, Derechos Humanos que son válidos no solo en un determinado colectivo societal sino en cualquier tiempo y en todo espacio donde exista el hombre. Esta investigación involucra diversas posiciones teóricas de diversos autores sobre el Estado, la ciudadanía y los Derechos Humanos tales como Hobbes (2003) Rousseau (2013) Guerrero (2000) y Tafur (2006), así como los principios estatuidos en la Declaración Universal de los Derechos Humanos (1948). En este artículo se relacionan los Derechos Humanos como correlativos de las obligaciones del Estado y de los ciudadanos. Se defiende la tesis respecto que las obligaciones del Estado hacia el ciudadano, como garante de los Derechos Humanos, exigen una corresponsabilidad por parte de éste como contrapartida en una relación bidireccional y necesaria, convertida en condición sine qua non, para que pueda asegurarse la existencia de la humanidad en el mundo contemporáneo.

1. Abogada de la Universidad Popular del Cesar (2013). Administradora Pública de la Escuela Superior de Administración Pública (2013). Magíster de la Universidad de Zulia en Gerencia de Empresa (2017). Docente de la Universidad Popular del Cesar. Directora del Centro de Investigación y Documentación Socio jurídica de la Universidad Popular del Cesar. Docente investigadora y Tutora del Semillero de Investigación Acepciones del derecho. Email: marthacharris@unicesar.edu.co Orcid: https://orcid.org/0000-0001-8519-3806

2. Doctor en Ciencias Políticas, Administrador de Empresas, Abogado, Especialista en Gestión Pública, Especialista en Administración Pública, Docente Investigador de la Escuela Superior de Administración Pública ESAP, Investigador de la Universidad Popular del Cesar UPG. Email: yesithpedroza@hotmail.com Orcid: https://orcid.org/0000-0002-5853-9987 


\section{Keywords}

Human rights, correlativity, citizen.

\section{Abstract}

Every human being, by this fact, has basic rights, human rights that are valid not only in a certain societal collective but in any time and in any space where man exists. This research involves various theoretical positions of various authors on the State, citizenship and human rights such as Hobbes (2003) Rousseau (2013) Guerrero (2000) and Tafur (2006), as well as the principles established in the universal declaration of human rights (1948). In this article, human rights are related as correlative of the obligations of the State and citizens. The thesis is defended that the obligations of the State towards the citizen, as guarantor of human rights, demand a co-responsibility on the part of the latter as a counterpart in a bidirectional and necessary relationship, converted into a sine qua non condition, so that the existence can be assured of humanity in the contemporary world. 


\section{INTRODUGGIÓN}

La otra cara de la moneda de un derecho es una obligación. Reclamar un derecho exige ineludiblemente la obligatoriedad de una acción que lo compense. Es indudable la relación de correlatividad, junto a obligaciones se ubican los derechos, el uno es condición del otro. En ese sentido, ¿Es valida la anterior premisa para el caso de los Derechos Humanos respecto a los deberes del ciudadano? Estudiar los Derechos Humanos desde la perspectiva de la correlatividad entraña la discusión sobre los deberes que le asisten al ciudadano de comprometerse o compensar lo que un tercero, un ente ficticio llamado Estado, le garantiza o debe garantizarle. La proposición: los derechos exigen un deber, expresa la necesidad de una responsabilidad como contraparte; situación que la coloca en fuente de debates que no pierden actualidad, pero, además, con una característica adicional en lo referente al deber como contrapartida del derecho; el de especificar que ésta contraparte debe ser voluntaria y no obligada por ningún ejercicio de coerción ejercido por un aparato externo al individuo.

La propuesta anterior es sustentada por el teórico político Thomas Hobbes (2003) quien en su libro El Leviatán expresa que, si alguien transfiere su derecho de libertad ilimitada, o renuncia a él, lo hace en consideración a cierto derecho que recíprocamente le ha sido transferido, o por algún otro bien que de ello espera. Desde esta perspectiva, la argumentación básica de Hobbes (2003) está cimentada en la premisa que la condición natural del hombre es de guerra de todos contra todos, en la cual cada individuo está gobernado por su propia razón. De aquí se sigue que, en semejante condición, cada hombre tiene derecho a hacer cualquier cosa, Incluso en el cuerpo de los demás. Por consiguiente, mientras persiste ese derecho natural de cada uno con respecto a todas las cosas, no puede haber seguridad para nadie, por fuerte o sabio que sea; de poder existir durante todo el tiempo que ordinariamente la Naturaleza le permite vivir a los hombres.

Se hace necesario considerar que la adquisición de un derecho, dentro de una organización humana colectiva, entraña la obligatoriedad de la renuncia de la libertad absoluta y por lo tanto, la exigencia de un precio a pagar, que se ve reflejado en un deber u obligación. Desde otra perspectiva, Rousseau (2013) propone su teoría del contrato social como una acción voluntaria y grupal de los ciudadanos; en la que éstos establecen un sujeto, a partir de la asociación de las individualidades, llamado pueblo, el cual, posteriormente, crea un ente para gobernar e imponer sus decisiones con instituciones que pueden llegar a utilizar, de ser necesaria, la fuerza a la que denominan coacción legitima. En este escenario, la persona, convertida en ciudadano, nueva categoría que aparece bajo la figura de un invento de la modernidad llamado Estado, puede actuar como ejecutor de las decisiones de la autoridad soberana, pero también como súbdito, en cuanto, está sometido a las imposiciones denominadas leyes del ente ficticio llamado Estado.

El acuerdo de los ciudadanos mediante el cual ceden parte de su libertad a un ente ficticio, para que este le devuelva en contraprestación unas acciones encaminadas 
a una vida colectiva lo más segura posible, es lo que Rousseau designa como el contrato social; este pacto origina a una personalidad colectiva, con carácter propio, conocido como la voluntad general. Esta voluntad general le concede unos derechos al ciudadano, pero a cambio éste debe aportar un pago compensatorio, llamados deberes. La Declaración Universal de Derechos Humanos (1948) como acuerdo de convivencia mundial, se edificó bajo la convicción de que el derecho humano es inherente a todo ente sobre la tierra que tenga la característica de ser un humano vivo, condición sine qua non, independiente de cualquier tipo de situación dada por su edad, sexo, raza, religión o cualquier otra variable, tampoco importa su ubicación espacio - temporal. Estos derechos le pertenecen a la raza humana, sin importar su ubicación espacial en cualquier lugar del universo, lo que la Declaración Universal de Derechos Humanos denomina la familia humana.

\section{Los Derechos Humanos constituyen un} tipo de derecho cuya particularidad radica en aquello que tienen de correlativo. El correlato de los Derechos Humanos es la obligación que tienen los Estados a respetar y a garantizar la vida y plena realización de los seres humanos. En consecuencia, se trata de derechos cuya obligación correlativa de defenderlos no es de quien tiene el derecho humano, sino de un tercero: el Estado; que es quien debe asegurar la existencia de los mismos. Esto quiere decir que los Derechos Humanos, a diferencia de otros derechos, no pueden perderse. Más aún: aunque un Estado no reconozca tales derechos este derecho existe igualmente para todo ser humano, pues éste lo posee por el hecho de ser humano. En este sentido, los
Derechos Humanos pueden definirse como inalienables. El que los Derechos Humanos sean inalienables contempla varios aspectos fundamentales:

a. Ninguna persona puede ser privada de ellos. Privar a un ciudadano de los Derechos Humanos es quitarle su condición humana, son condiciones sine qua non, las personas no pueden desprenderse de sus Derechos Humanos porque son inherentes a su existencia.

b. Deben ser respetados y defendidos por la legislación de todos los Estados, ya sean occidentales u orientales, cristianos, budistas o islamistas, ya que los Derechos Humanos deben estar por encima de credos y religiones.

c. Han de servir como marco de referencia para organizar la vida social y política, la vida colectiva en comunidad exige no solo el conocimiento de estos derechos, sino la divulgación, la creación de programas y proyectos que los instituyan y fortalezcan, pues, en la medida que tomemos conciencia de éstos se irán consolidando los valores que encabezan el preámbulo de los Derechos Humanos: libertad, justicia y paz porque en una sociedad donde exista libertad con justicia la consecuencia lógica debe ser la armonía general. Y,

d. Han de constituir el código básico y fundamental de la justicia de todas las naciones y del Derecho Internacional dado que lo que se busca, como lo indica el segundo considerando de la declaración de los Derechos Humanos es: el advenimiento de un mundo en que los seres humanos, liberados del temor y de la miseria, disfruten de la libertad 
de palabra y de creencias como ejes primarios fundamentales.

Todo lo anterior lleva a formular la siguiente interrogante: ¿En qué consiste el fenómeno de la correlatividad de los Derechos Humanos frente a la ciudadanía en el Estado?

\section{Metodología}

Esta investigación cualitativa se enmarca dentro del tipo de los estudios documentales, utilizando como técnica la hermenéutica, para lo cual se realizó el análisis desde la vertiente de algunos autores, así como de la doctrina existente proveniente de instrumentos de derecho internacional, con el propósito de analizar la correlatividad de los Derechos Humanos respecto de los deberes del ciudadano con relación al Estado.

\section{Los Derechos Humanos}

Si bien los Derechos Humanos como obligación estatal y defendidos a nivel internacional por la sociedad global y por los organismos internacionales creados para este fin inician su accionar a partir de 1948, año en que fueron adoptados por la asamblea de las Naciones Unidas, sus orígenes se remontan al nacimiento mismo de las normas de derecho en occidente con las culturas griegas y latinas, sobre todo. Otros teóricos se remontan a tiempos más antiguos y proponen que los Derechos Humanos nacen como acuerdo social desde el momento en el que hombre decide asociarse y crear reglas de convivencia, es decir, cuando decide abandonar su libertad natural ilimitada y someterse a un acuerdo entre individuos que conviven en el mismo territorio o en territorios cercanos, y someterse a sus restricciones y reglamentaciones.

La Enciclopedia Jurídica Omeba (1963) sobre el derecho natural coincide con la afirmación de que el status natural fenece y que por acuerdo los hombres coinciden en abandonarlo para pasar al status societatis, tránsito que se opera merced a un contrato, por el cual los hombres se obligan a una convivencia pacífica y de mutuo respeto (pactum unionis) en forma voluntaria a través de un contrato social o sometidos por la fuerza ejercida por un ente externo. Siguiendo lo propuesto por ésta enciclopedia, en el momento que aparece el pueblo, que surge como tal por pactum unionis, dejando de ser una mera multitud disgregada, el ciudadano se subordina a un gobierno que el mismo designa, lo cual resulta de un contrato en lo político (pactum subientionis), con lo cual aflora lo esencial de esta doctrina, que es poner de relieve que el poder político es emancipación del pueblo, y al reivindicar para éste su derecho al ciudadano es exaltado al primer plano de la vida política del Estado; pero esta emancipación conlleva una premisa esencial: los ciudadanos gozan a partir de ese momento de unas prerrogativas que no tenían antes entre esas la garantía de gozar de unos derechos fundamentales: los Derechos Humanos.

Los Derechos Humanos son, en esencia, unos derechos tan básicos que sin ellos resulta difícil llevar una vida digna. La Declaración Universal de los Derechos Humanos suscrita en 1948 establece como características de éstos los siguientes: 1) Universales: pertenecen a todos los seres humanos. Son unas exigencias mínimas que 
se deben garantizar en reconocimiento de su condición de humanos. 2) Prioritarios: al entrar en conflicto con otros derechos, tienen que ser protegidos de una forma prioritaria, están incluso por encima del derecho Estatal y 3) Innegociables: ninguna sociedad debe negar la protección de estos derechos a sus miembros. Además, todas las sociedades tienen que contribuir en el contexto mundial para lograr que se respeten los derechos de todas las personas, sea cual fuere la sociedad concreta a la que pertenezcan. Para que los Derechos Humanos sean efectivos, es decir, les brinden a los ciudadanos las garantías de una vida digna y en condiciones que le permitan buscar el ideal griego de la felicidad colectiva se debe dar una relación correlativa entre los deberes del ciudadano frente al Estado y las obligaciones de éste. El Estado, como órgano político y detentor del aparato de coerción, debe garantizar la efectividad de los Derechos Humanos, no basta anunciarlos deben ser vivenciados por la población del mismo, y por otra parte; el ciudadano, en contraprestación y procurando su propia seguridad, propende por la subsistencia del Estado al que está sometido o con el que ha firmado el contrato social construyendo un circulo virtuoso.

La primera acción corresponsable por parte de la ciudadanía de un Estado, es el auto reconocimiento como súbdito, el sometimiento en forma voluntaria a su poder y organización como manifestación de la transacción en la que el ciudadano que suscribe el contrato le entrega parte de su libertad al Estado para ser objeto de obligaciones así como también ser sujeto de derechos, con la condición que este sometimiento esté regulado por normas, por leyes que procuren un equilibrio entre todos los individuos que componen el Estado, así como también la existencia de armonía entre éste y el ciudadano. Para el escritor y político francés Maximilien Robespierre (2000) debe existir un orden en el Estado sin distinciones y en relación bidireccional; lo que los atenienses en la Grecia antigua llamaron a isonomia, definida como el concepto de igualdad de derechos civiles y políticos de los ciudadanos; en el que el ciudadano se encuentre sometido al magistrado, el magistrado al pueblo y el pueblo a la justicia entendiendo por justicia una conformidad entre todos los ciudadanos que habiten en forma colectiva un territorio determinado.

Sobre la noción de Estado Aristóteles expresa que el Estado es una asociación de ciudadanos que obedecen a una misma constitución; esta obediencia exige como contraprestación garantías, entre ellas la de gozar de derechos naturales, civiles y políticos. Éstos, los derechos, pertenecen al ciudadano, entendido en sentido amplio que inmiscuye a todo ser humano que hace parte de una sociedad, no restringido como lo que se entendía en la Grecia antiguo, como sujeto político capaz de mandar y obedecer, de crear situaciones políticas colectivas donde prime lo grupal sobre lo individual, es decir, es una situación de ponderación de la libertad propia.

\section{LA GIUDADANíA}

Aristóteles, en sus escritos sobre la política, establece que el rango eminentemente distintivo del verdadero ciudadano se evidencia en el goce, es decir en el derecho, que tiene de las funciones de juez y magistrado donde, además, pueda tener en la asamblea pública y en el tribunal voz deliberante, cualquiera que sea. Se entiende que la persona que se somete al Estado, como ente 
político, lo hace con la intención de adquirir como situación correlativa unos derechos en contraprestación, entre los que se encuentran en primer nivel los denominados Derechos Humanos.

Sobre la calidad de ciudadano, la Corte Constitucional de Colombia en sentencia C-591 de 2012, con ponencia del magistrado Jorge Iván Palacio dictaminó que ésta es adquirida por los nacionales colombianos cuando alcanzan la mayoría de edad, que mientras la ley no disponga otra cosa se da a partir de los dieciocho años. Esta posición refleja la actividad del ciudadano condicionada a su edad y no a su actuar dentro de la sociedad. La ciudadanía entraña una participación activa en las problemáticas sociales, una actividad continua que reclama del individuo posiciones y acciones frente a su sociedad; asumiendo posturas axiológicas o políticas en cuanto a los problemas sociales o respecto de la construcción de un proyecto de nación e incluso frente a los problemas que colocan en entredicho la subsistencia de la misma humanidad.

Hablar de la condición de ciudadanía es complicado por cuanto múltiples corrientes filosóficas le dan connotaciones diferentes. Algunas proponen que el ciudadano es un elemento de poder dentro de un contexto colectivo particular donde hay multiplicidad de intereses diversos y en las mayorías de las veces contradictorio. En ese orden de ideas, la ciudadanía es una facultad política que involucra un asunto de lucha social formado a través de ciclos y enfrentamientos históricos poniendo en juego hasta la vida misma de las personas que han luchado por adquirir esta calidad. La ciudadanía es un instrumento jurídico que equipara a las personas a pesar de cualquier diferencia fisica, ideológica, religioso, entre otros. Pero, además, la ciudadanía implica la conformación de espacios públicos para el debate, el espacio foral griego de la polis; lo que se denomina por parte de Guerrero (1998) la opinión pública, el espacio por antonomasia para la dialéctica. También implica la ciudadanía, por otra parte, según Toro (2000) la construcción de lo público, especialmente lo referente a la opinión pública.

Zapata-Barrero (2001) propone que ser ciudadano implica tener la capacidad de mandar y ser mandado, de gobernar y ser gobernado, esto es, el derecho de participar en el poder del gobierno o de elegirlo. Se insiste en la existencia de una relación bidireccional, en un doble sentido: como autoridad en el diseño de las deliberaciones políticas y como obediente de las deliberaciones afectadas por otros. Esta bidireccionalidad es, de hecho, el núcleo de la definición aristotélica de ciudadano que la tradición cívico-humanista ha retenido literalmente hasta nuestros días: el ciudadano obedece a las restricciones que el gobierno le impone puesto que es el mismo quien ha participado en su elaboración.

\section{LA GORRELATIVIDAD DE LOS Derechos Humanos}

El Estado, entonces, tiene la obligatoriedad correlativa, frente a los deberes del ciudadano, de construir instituciones políticas - jurídicas que den respuestas a las necesidades e intereses de los ciudadanos, dado que para modificar la sociedad se requiere de éstas, así como también a la preservación y goce los Derechos Humanos. Las instituciones son definidas por Toro (2000) como ordenamientos o reglas que 
permiten prevenir o solucionar problemas sociales de la ciudadanía actual; ciudadanos proactivos, arquitectos de nuevas formas de democracias, a las que dan forma y vida, no sólo como objetos pasivos de derechos y deberes, sino como protagonistas de esos derechos para ejercerlos al mismo tiempo que asumen responsabilidades sociales ante las problemáticas de la comunidad.

En la triangulación Estado - Derechos Humanos - Ciudadano, se observa que cada uno de estos elementos tiene un derecho, a reclamar o a imponer y como contraprestación una obligación, también que se puede reclamar o que se debe cumplir, a este proceso es lo que hemos denominado la correlatividad de los Derechos Humanos, es decir, la relación entre la responsabilidad y la obligación para intentar relacionar los conceptos de Derechos Humanos y ciudadanía. Recordemos que, la correlatividad entre el Estado y los Derechos Humanos se da como garante el primero de lo segundo y la correlatividad entre el ciudadano y el Estado como compensación para que le establezca garantías, es decir, derechos y responsabilidad u obligaciones.

El derecho humano, desde una óptica más jurídica, como correlatividad de la obligación, es entendido como un atributo de la conducta humana, de las personas o del ciudadano como sujeto y objeto del poder, ya sean jurídicas o naturales. El código civil colombiano, define los derechos personales en su artículo 666 como los que pueden reclamarse de ciertas personas, por un hecho suyo o la sola obligación de la ley de las que han contraído obligaciones correlativas de las que nacen las acciones personales.
Respecto a la clasificación del derecho, como institución jurídica, el jurista colombiano Álvaro Tafur (2006) explica que los derechos reales son aquellos que nos garantizan el goce completo de una cosa exterior (propiedad), incluso la facultad de disponer de la cosa; o el goce limitado de una cosa exterior cuya propiedad pertenece a otro (derecho de la cosa ajena). Para el citado autor la diferencia de los derechos reales respecto de los demás derechos absolutos, como los Derechos Humanos, consiste en que las cosas de las cuales se tiene goce completo o limitado son exteriores a quien lo tiene, y en consecuencia pueden corresponder a una persona lo mismo que a otras muchas, es decir, que para el caso que nos ocupa de los Derechos Humanos no se pueden identificar como derechos reales dado que no son cosas que pueden existir indistintamente del ser humano, éstos sólo existen por la misma vida de las personas y no se pueden disponer de ellos como objetos.

En contraposición con lo expuesto anteriormente los Derechos Humanos se registran en los que la normatividad colombiana, llama un derecho personal, que es la otra división propuesta por el derecho civil, según Tafur (2006) éste derecho de identifican como los que pueden reclamarse con respecto de una cierta persona natural o jurídica, en este caso, el Estado representado en la Nación y cuya fuente de la obligación es la ley respecto de las personas, es decir, sus ciudadanos.

Los Derechos Humanos, como derechos personales, pueden gozarse de manera ilimitada por cada uno de nosotros, los ciudadanos, limitado sólo por el derecho al goce de los demás sujetos, es decir de las otras 
personas que conviven con nosotros en un territorio determinado. Dentro de algunos de los bienes jurídicos a los que la ciudadanía tiene derecho podemos mencionar: el derecho a la justicia, educación, salud, recreación participación política, etc. Se percibe nuevamente la correlatividad por el Estado de proveer y del ciudadano de respaldar.

La Enciclopedia Jurídica Omeba (1963) afirma que el derecho tiene su principio en la naturaleza y esencia del hombre, como persona en absoluto. Este carácter, que constituye el centro y el eje de las relaciones de convivencia, cobra así un significado específicamente jurídico, cuyo sentido se concreta en la máxima de que todo hombre, sólo a fuerza de tal, puede exigir que sea respetado por todos, como el mismo está obligado a respetar por sí mismo el imperativo, no extendiendo el arbitrio suyo hasta imponerlo a otros, no sometiendo su voluntad a quien por naturaleza sólo está sujeto a sí mismo. Es decir, que los Derechos Humanos deben ser defendidos para el uso personal pero también para el uso social - colectivo. La postura anterior cimenta lo apuntado anteriormente, en este artículo, los Derechos Humanos son de la persona, de su esencia y materializados a partir de la suscripción del contrato con el Estado y la obligación ciudadana, en contraprestación, de defender la existencia de éste.

El concepto persona engloba toda la especie humana y por lo tanto cuando se habla de Derechos Humanos se está referenciando a todo ser que tenga la esencia y características de ser humano. De allí que la idea de un derecho universalmente propio de la persona, innato en ella y jamás reducible a alguna concreta relación de convivencia, pueden ser medidas y constituidas todas las relaciones sociales, de modo que cada una de ellas, cualquiera que sea su particular especie, lleve en sí el sello de aquel derecho, y suponga e implique el reconocimiento de aquella suprema virtualidad del ser autónomo, representando de hecho un ejercicio o función de la misma.

Es necesario aclarar que la persona de la que se habla aquí engloba la universalidad del sujeto natural; aquella universalidad que se concreta en diversas figuras individuales y representa la esencia común y valor eterno de la humanidad como una sola especie.

La contraparte, como venimos sosteniendo desde el introito de este escrito, del derecho es el deber que entraña una obligación, pues, toda responsabilidad obliga. Siguiendo al Código Civil Colombiano, que se inspiró en el Código Civil Francés, también conocido como Código napoleónico, a dar, hacer o no hacer. Para Kelsen (2000) la obligación se entiende como la posibilidad de conducirse de una manera determinada cuando la conducta opuesta es la condición de una sanción o un castigo. En la correlatividad de los Derechos Humanos, se mantiene la tesis que la obligación se da en doble sentido, del Estado para el ciudadano y lo contrario.

El compromiso frente al Estado por parte del ciudadano se da respecto al pago de impuestos, al cumplimiento de las normas jurídicas, o incluso, el acto de ofrendar la vida en defensa de la existencia de éste, la sanción ante el incumplimiento se manifiesta en una pena, una multa o cualquier otro actuar en la que se utilice el poder de coerción legitima. Mientras que, en el caso de los Derechos 
Humanos del ciudadano, con relación al Estado, la sanción por el no cumplimiento de la obligación, como garante que éste tiene ante el ciudadano es de tipo internacional o incluso insurreccional, tal como lo contempla la carta de los Derechos Humanos expedida por la ONU en 1948. El ciudadano tiene el derecho natural de oponerse al tipo de gobierno o de Estado que no le da garantías de sus Derechos Humanos y por lo tanto pueda legitimarse un alzamiento en contra del mismo Estado con ánimo de procurarse otro que le de las garantías que desea. En este sentido, se expresa el considerando número tres de la Declaración de los Derechos Humanos como esencial que los Derechos Humanos sean protegidos por un régimen de derecho, a fin de que el hombre no se vea compelido al supremo recurso de la rebelión contra la tiranía y la opresión.

Por su parte el escritor chileno Vodanovic (1970) define la obligación como una relación jurídica entre dos personas determinadas por virtud de la cual una de ellas, el deudor, se encuentra en la necesidad de realizar una prestación en interés de la otra, el acreedor, que puede exigírsela. Para el ejercicio de los Derechos Humanos es el Estado quien está en el deber de realizar una prestación en interés del ciudadano: garantizar sus Derechos Humanos en tanto sea parte de la raza humana, es decir, sus derechos naturales, pero también éste asume una obligación con el Estado como compensación, someterse y procurar su existencia y subsistencia.

\section{LA ESTRATEGIA DE LA PARTICIPACIÓN GIUDADANA}

En la actualidad, en los llamados Estados social de derecho, la ciudadanía es diferente a la planteada con el nacimiento del acuerdo social roussoniano; hoy el ciudadano es proactivo, reclamando el derecho a participar y a coadyuvar con los gobiernos o de manera independiente en la construcción de estrategias y acciones que conlleven a la fundamentación y mantenimiento del Estado, sobre todo en los Estados democráticos en pleno inicio del siglo XXI, dado que hoy existe una mayor demanda por parte de los ciudadanos de incidir en decisiones y acciones concretas. Este nuevo papel asumido por parte del ciudadano tiene causas diversas; el modelo económico, los avances tecnológicos con las redes de información en el ciber espacio, pero ante todo porque las instituciones estatales y gubernamentales han mostrado una baja capacidad de respuesta a la creciente complejidad de demandas reales por parte de la comunidad, esta afirmación se constata con sólo hacer una rápida mirada a los medios de comunicación masivos de Colombia, Venezuela o cualquier otro país latinoamericano; periódicos, revistas, programas de televisión, redes sociales que en forma ininterrumpida están informando sobre las inconformidades de las comunidades por la no solución de sus problemáticas cotidianas.

Es en los aspectos de la vida diaria es donde existe mayor dificultad para los gobiernos, como aparato del Estado, para dar respuestas inmediatas a problemas habituales como la reparación de una calle, el cambio de redes eléctricas, de agua potable o el mal servicio de los establecimientos públicos dedicado a la salud, que a situaciones más complejas como la ejecución de una gran obra urbanística. El ciudadano de hoy es, sin duda, más consciente de su papel en el mantenimiento del aparato estatal para que en contraprestación el Estado 
le asegure instituciones sociales, instrumentos jurídicos, estructuras gubernamentales y políticas públicas que le permiten vivir y convivir bajo condiciones cada día más favorables. Es decir, hay más conciencia de la correlatividad de los derechos y deberes, entre ellos los esenciales: los Derechos Humanos.

Pero, para que la conducta descrita anterior se mantenga y se extienda en la conciencia de la ciudadanía es importante que los gobiernos establezcan políticas públicas, estrategias y/o herramientas político - jurídicas en las que obliguen ellos, pero también que motiven u constriñan al ciudadano a participar en el mantenimiento del status quo y en la consolidación de los derechos Humanos como políticas estatales. La participación ciudadana debe ser el eje estructural de los mecanismos que aseguren el sostén del Estado, con la ejecución de acciones asumidas por el ciudadano como contraprestación hacia éste por garantizar sus Derechos. En consecuencia, para vigorizar la intervención de la ciudadanía se necesita que la comunidad tome conciencia de su papel como solucionador, autónomo o asociado del Estado, de las diferentes problemáticas nacionales, regionales, locales e incluso mundiales. Pero también, por el otro lado y en dirección contraria, se requiere un proyecto de nación liderado desde los más internos mecanismos de poder del Estado, desde sus élites, donde el aparato ideológico que lo sustenta se comprometan todos los poderes que lo manejan: el poder económico, el religiosos, los proyectos políticos, incluso desde la misma cultura, en general la sociedad civil con sus organizaciones no pertenecientes al aparato estatal, para la edificación de una ética colectiva y una formación del ciudadano en la construcción de un proyecto ideal de Estado - nación con la participación ciudadana activa y proactiva.

\section{Conclusión}

La implementación de una participación ciudadana activa debe partir desde aquellos asuntos que afectan directamente al ciudadano en su comunidad, desde lo local, pero trabajar al mismo tiempo en la realización de un compromiso con los problemas nacionales o globales por analogías con las experiencias locales. Por ello, sin una verdadera experiencia local es difícil una sólida conciencia global. No puede haber conciencia sin experiencia y la participación ciudadana permite a los ciudadanos obtener esa experiencia como un servicio público más, que le alimente como persona y ciudadano, como es la propia educación primaria o el servicio de bibliotecas públicas, por citar sólo algunas. La ejecución de estrategias de participación ciudadana provocará que las políticas públicas, los planes y los proyectos que son emprendidas por el aparato gubernamental del Estado se sientan como propios para los ciudadanos y que por lo tanto genere actitudes en la conservación y buen uso de las obras o servicios que se hagan sintiéndolos como propios, así como alertar a tiempo de los posibles contratiempos o desperfectos redundando todo esto en una mejor disposición del ciudadano en la defensa y subsistencia del Estado consolidado la correlatividad de los Derechos Humanos como eje transversal. El ciudadano ideal, entonces, es un constructor de ciudadanía dado que entiende que en la medida que ayude a organizar las instituciones sociales están garantizando la fortaleza del Estado y como consecuencia éste le garantiza unas 
condiciones de vida digna con derechos, entre ellos los Derechos Humanos, creando un circulo virtuoso, inacabado, dinámico y si se quiere eterno, tan eterno como sea la humanidad.

\section{REFERENGIAS}

Aristóteles. (2013). La política. Ediciones universales. Bogotá, Colombia.

Declaración Universal de Derechos Humanos. (1948). OP graficas Ltda. Bogotá. Colombia.

Enciclopedia Jurídica Omeba. (1963). Editorial bibliográfica argentina. Buenos Aires, Argentina.

Guerrero, Omar. (1998). La Administración y los Públicos. La Investigación en la Administración Pública, Hoy. Casos Exitosos. Imprenta Nacional. Bogotá, Colombia.

Hobbes, Thomas. (2003). Leviatán. Editorial Losada. Buenos Aires, Argentina.

Kelsen, Hans. (2000). Teoría pura del derecho. Editorial Unión Limitada. Bogotá, Colombia.

Rosseau, Jean - Jaques. (2013). El contrato social. Ediciones Istmo S.A. Madrid, España.

Roberspierre, Maximiliano. (2000). Libertad, igualdad, fraternidad. Errerpar S.A. Buenos Aires, Argentina.

Tafur González, Álvaro. (2006) Código civil anotado. Editorial leyer. Bogotá, Colombia.

Toro, José Bernardo. (2000). La construcción de lo Público desde la Sociedad Civil. Ponencia en el V encuentro del tercer sector, Cartagena de indias, Colombia, 2000.

Vodanovic, Antonio. (1970) Derecho de obligaciones. Ediciones periodísticas y estadísticas. Santiago, Chile.

Zapata - Barrero, Ricard. (2001) Ciudadanía, democracia y pluralismo cultural: hacia un nuevo contrato social. Editorial Anthropos. Barcelona, España. 